\section{NON-PEROXIDE TOOTH WHITENING KITS} provider of non-peroxide teeth whitening products, created by 20 -something brothers Ollie and Toby Brittan and their friend Tom Jansons at the end of 2019.

Whites Beaconsfield specialise in nonperoxide teeth whitening kits that show results after just ten minutes and range in price from $£ 9.99$ to $£ 114.99$. The products vary from single items to ultimate teeth whitening kits. The extensively researched natural, vegan-friendly oral care products are guaranteed to give cleaner teeth and a sparkly smile, naturally.

The non-peroxide products have been very successful so far, even during the COVID-19 pandemic, because of their low cost and convenience and because they guarantee results.
Whites Beaconsfield is the UK's leading
Whites Beaconsfield have also launched the Bright Smiles Foundation with 50p of every order from Whites Beaconsfield being donated to an incredible cause. The funds raised will build schools in the most deprived areas of Ghana, Guatemala and Laos.

For the full product range visit www. whitesbeaconsfield.co.uk.

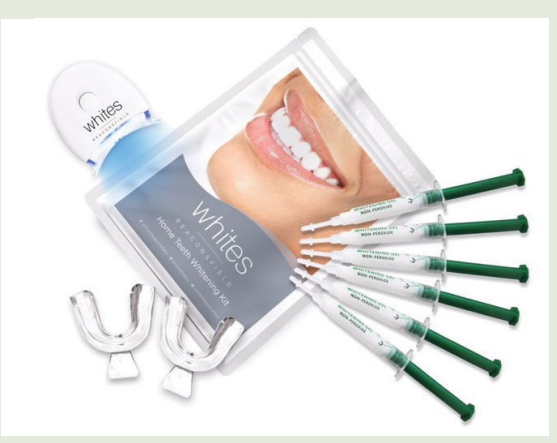

\section{CURVY, CONTOURED HAND INSTRUMENTS}

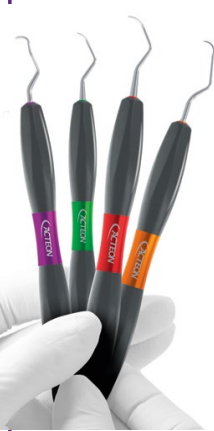

Acteon UK has just

launched a new range of hand instruments called Bliss. They are strikingly different to most other instruments on the market. Curvy and contoured to maximise comfort, the first thing you'll notice is the urge to actually hold one. The second thing you'll notice is the soft silicone touch and the way it fits snugly in your working hand. You might even forget it's there because it is so lightweight, only $15 \mathrm{~g}$.

Bliss hand instruments have been designed by clinicians, working closely with the experienced manufacturers at Acteon. Not only is the handle shape new, but the tips have also been adjusted to maximise performance and improve access in hard to reach areas.

The pentagonal, flat sided grip design is much more comfortable than typical cylindrical machined grips allowing for superior tactile feedback. The high quality stainless steel used and the production process itself produces tips that are harder wearing and stay sharper for longer. The different instrument types are colour coded for easy recognition and can be personalised.

This combination of comfort, feel, hardness and sharpness ensures that users have to use less force, suffer less hand fatigue and patients experience a much enhanced, lighter and faster treatment.

Acteon UK specialises in the manufacture and supply of minimally invasive innovative technologies for dentists and dental professionals to diagnose, treat and educate patients efficiently.

For more information call 0800038 9840 (ext 1), email Marianne.maguire@ acteongroup.com or visit acteongroup.com/ uk-en.

\section{OUTSOURCE PAYROLL FOR EFFICIENCY IN A CHANGING LANDSCAPE}

As dentistry adjusts to Brexit, your practice must support smoother workflows during the transition. Payroll is one area where outsourcing will save money and time.

Whether your practice is large or small, Wagemate is a specialist payroll service that will manage everything. You will get peace of mind that people will be paid accurately and that you are compliant with HMRC's regulations.

Contact Wagemate today, tel: 03330

102102 or email info@wagemate.com.
THE ART OF QUALITY AT YOUR FINGERTIPS

For over 600 years, has been supplying dental instruments of unrivalled quality, supporting clinicians in achieving

outstanding results for their patients.

Quintess Denta offers the full Medesy product range to dentists in the UK and Ireland - an incredible 3,000 items steeped in a long history of excellence.

Within the ranges available are tools for diagnostics, periodontal care, surgical treatment, orthodontics, restorative work and implantology. Myriad accessories are also available, as are lab-focused items. In addition, bespoke kits can be made to order, fulfilling your needs to a tee.

Encompassing six centuries of Maniago blacksmiths' expertise, this market leader's prestigious, certified, stainless steel instruments are streets ahead of the competition.

For further information, contact Ian Creighton on +353 (0)1 691 8870, email ian@quintessdenta.com or visit quintessdenta.com/pages/ medesy-navigation. Italian-based Medesy

\section{SAFEGUARD THEIR SMILES

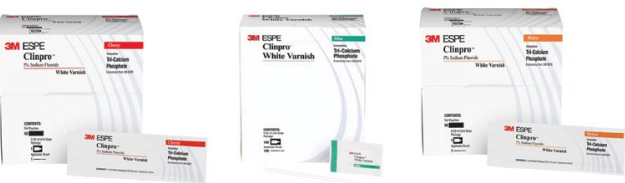

When faced with patients who are at high risk of developing caries, Clinpro White Varnish with TCP from 3M Oral Care is an effective shield that not only protects healthy dentition but also helps to preserve restored teeth too.

Easy to apply and with a high fluoride content that acts to defend against plaque acid in the oral cavity, Clinpro White

Varnish with TCP from $3 \mathrm{M}$ is an effective barrier that can easily help high-risk patients retain a healthy smile.

For more information, call 0845873 4066 or visit www.3m.co.uk/Dental. 3M and Clinpro are trademarks of the $3 \mathrm{M}$ Company. 